UWS -

THE FLUX OF METEORS

AND METEOROTDS

IN THE NEIGHBORHOOD

OF THE EARTH

C. S. NILSSON and R. B. SOUTHWORTH
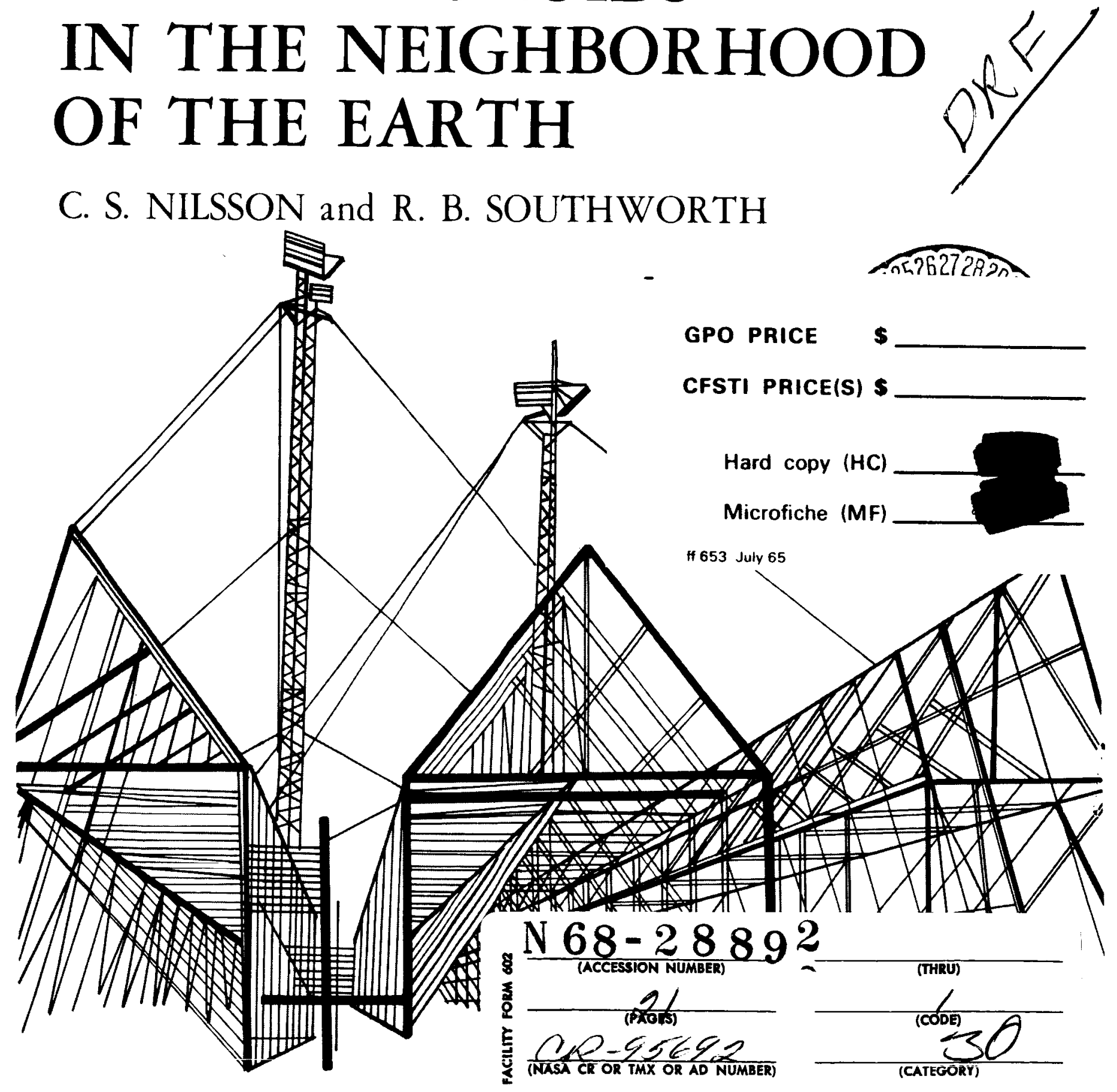

Smithsonian Astrophysical Observatory SPECIAL REPORT 263 
Research in Space Science

SAO Special Report No. 263

THE FLUX OF METEORS AND MICROMETEOROIDS IN THE NEIGHBORHOOD OF THE EARTH

C. S. Nilss on and R. B. Southworth

December 27, 1967

Smithsonian Institution Astrophysical Observatory Cambridge, Massachusetts 02138 
$\underline{\text { Section }}$

Page

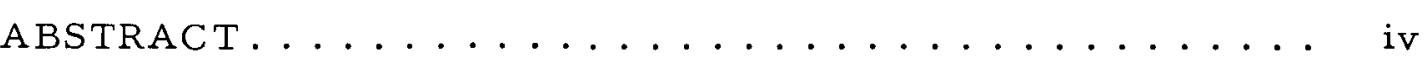

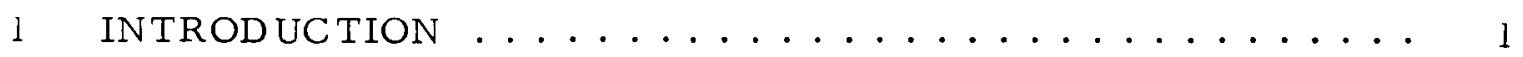

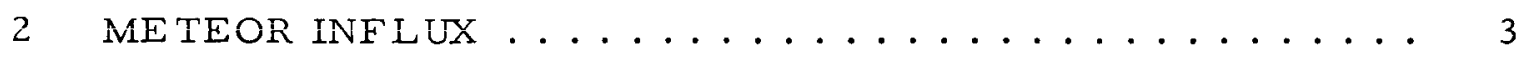

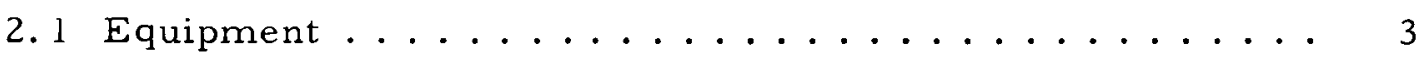

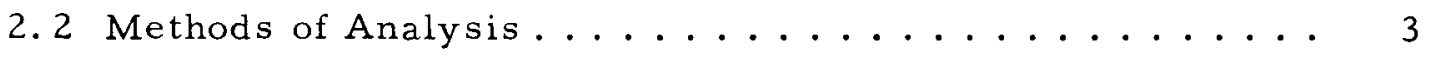

2.3 Discussion of Results.................... 4

3 MICROMETEOROID FLUX ..................... 7

3.1 Equipment ........................ 7

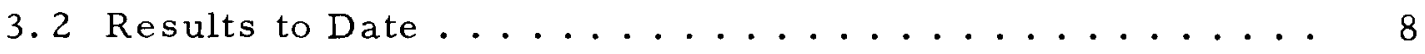

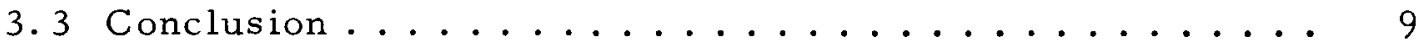

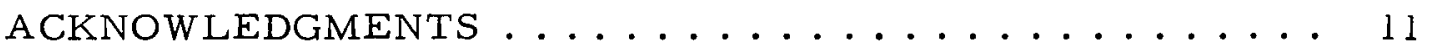

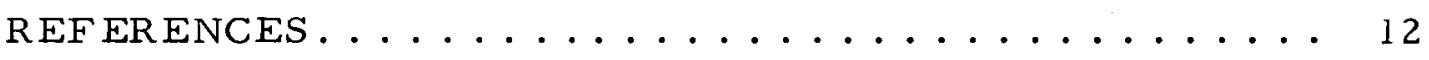

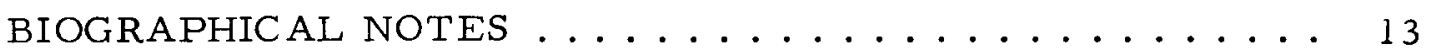




\section{LIST OF ILLUSTRATIONS}

$\underline{\text { Figure }}$

$\underline{\text { Page }}$

1 Top: The expected annual variation of meteor rate for constant $F$, plotted on the same scale as below. Bottom:

Calculated values of $\mathrm{F}$ in meteors $\mathrm{km}^{-2} \mathrm{hr}^{-1}$, the flux per unit solid angle of the celestial sphere producing trails of maximum line densities $>3.9 \times 10^{11}$ electron $\mathrm{m}^{-1} \ldots \ldots$

2 The calculated values of slopes of the cumulative flux versus sensitivity regression analyses................ 6

3 The basic OGO-2 micrometeoroid detector tube........ 8

4 Cumulative flux versus mass curves based on data from various sources (originally drawn by C. W. McCracken and M. Dubin, NASA Tech. Note X-613-63-185,1963)..... 10 


\begin{abstract}
This report briefly presents the results to date of two continuing programs, viz., the measurements of radio meteor flux at Havana, Illinois, and the measurement of micrometeoroid flux on the OGO-2 satellite.

The average cumulative radio meteor influx as a function of mass is given by $\log \mathrm{I}=-14.0-1.05 \log \mathrm{m}_{\infty}$, where $\mathrm{I}$ is the influx in meteors per square meter per second, and $\mathrm{m}_{\infty}$ is the meteor mass in grams.

No more than two impacts of micrometeoroids of mass greater than $10^{-12} \mathrm{gm}$ have been recorded by the OGO-2 satellite experiment. This fact suggests that the average cumulative flux of such particles during the period October 1965 through March 1966 is less than $3 \times 10^{-2}$ particles $\mathrm{m}^{-2} \mathrm{sec}^{-1}$ $\left(2 \pi\right.$ ster $^{-1}$.

From these and other results it appears that the re is no radical departure from the constant mass per magnitude distribution of meteoric material in the neighborhood of the earth.
\end{abstract}




\section{RÉSUMÉ}

Ce rapport présente brièvement les derniers résultats de deux programmes en cours, à savoir les mesures de flux de radio météores à Havana (Illinois), et les mesures du flux de micrométéroides reçu par le satellite OGO-2.

Le flux incident cumulé moyen de radio météores est donné en fonction de la masse par $\log I=-14,0-1,05 \log \mathrm{m}_{\infty}$, où I est le flux incident en météores par mètre carré, par seconde, et $m_{\infty}$, la masse du météore en grammes.

Parmi les imp „cts enregistrés au cours de l'expérience du satellice oGO-2, deux seulement provenaient de micrométéorides de màsse supérieure à $10^{-12} \mathrm{gm}$. Ce fait laisse à penser que, pendant la période allant d'octobre 1965 jusqu'à mars 1966, le flux moyen cumulé de telles particules ne dépassait pas $3 \times 10^{-2}$ particules $\mathrm{m}^{-2} \sec ^{-1}(2 \pi \text { sterad. })^{-1}$.

Ces résultats ainsi que certains autres montrent que la distribution de matériau météorique ne s'écarte pas de manière importante de la loi de masse constante à grandeur constante, au voisinage de la terre. 


\section{KOHCIEK'I'}

у этом цокладе кратко пинводятся сониемннные результаты

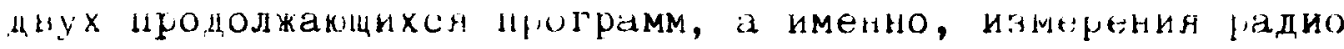

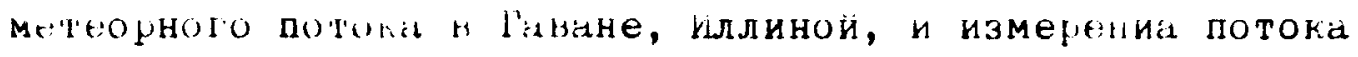
микрометеuinhx тел на UlO-L cпутнике.

Среднии кумулнтинный јадио метеорный приток, как пункјия массы, даетсн $\log I$ - $14,0-1,05 \log \mathrm{m}_{\infty}$, Где I является метеорным пинтоком на квадратный метр в секунду и т malcoǘ meteopa h l’piamaix.

He оoлte цвух удыров микрометеоров с массой вольшей чем $10^{-12} \mathrm{gm}$ онли записаны при опыте с ого-2 спутником. Этот факт наводит на мисль что среднй̆ кумулятивный поток таковых частьн в периуд ит октяоря 19б5г. до марта 1уб6г., является мetibe чем $3 \times 10^{-2}$ частиц ч $^{-2} \operatorname{cek}^{-1}(2 \pi s t e r)^{-1}$.

Ha основе этих и других результатов кажется что не имеется основного отклонения от постоянного распрепеления массы по величине метеорного материала поолизости с землей. 


\title{
THE FLUX OF METEORS AND MICROMETEOROIDS IN THE NEIGHBORHOOD OF THE EARTH*
}

\author{
C. S. Nilss on and R. B. Southworth
}

\section{INTRODUCTION}

This paper presents some results concerning the cumulative influx of meteors and micrometeoroids during the period 1965 to 1967 . The meteor data were obtained from the Havana meteor equipment operated by the Smithsonian Astrophysical Observatory, Cambridge, Massachusetts; the micrometeoroid data, from a detector on the Orbiting Geophysical Observatory, OGO-2, launched in October 1965 from California into a polar orbit of low eccentricity.

The technique of measuring micrometeoroid flux with the detector described in Section 3 is very straightforward, but the method of measuring the influx of meteors with the Havana radio meteor equipment warrants some introductory remarks.

With a given transmitter power and preset limiting receiver sensitivity, the meteor equipment will count a meteor every time the returned radar echo from the meteor trail exceeds the appropriate magnitude. There are many factors to consider in order to relate these echo counts to meaningful meteor influx values.

The Radio Meteor Project work was done under NASA Contract NSR 09-015-033. The OGO-2 data reduction was done under NASA Contract NAS 5-11007. *i*

Presented at the International Astronomical Union Symposium, Commission No. 33, Physics and Dynamics of Meteors, Tatranska Lomnica, Czechoslovakia, September 1967. 
First, one has to relate the electron density of a meteor trail to the strength of the received echo. This relation depends on the various radar parameters, including antenna gain in the appropriate direction. As individual echo directions are not recorded, the echo counts represent the integrated system response over all the sky. Thus, for example, to determine theoretically the variation of echo counts with time, it is necessary to know the distribution of meteor radiants over the celestial sphere. Elford and Hawkins (1964) have discussed these problems in some detail for the Havana meteor equipment and have derived numerical relations between echo counts and meteor influx, $F$, as a function of equipment sensitivity, $S$. It is the purpose of this paper to treat the latest echo-count data in terms of their work, and so derive the latest influx values. If we are to relate influx to meteor mass, it is necessary to know the relation between meteor mass and electron trail density. This is a separate and difficult problem, and we simply use the latest figures derived by Verniani and Hawkins (1965). 


\section{METEOR INFLUX}

\subsection{Equipment}

The observed meteor rates are recorded automatically from an Echo Analyzer designed and built by M. Schaffner for this project. This device counts the number of meteor echoes received in given intervals of time down to four different limiting receiver sensitivities, which cover the useful dynamic range of the system. This is about two orders of magnitude in receiver sensitivity. The data for each day include the echo counts for each receiver level sample at least once every half hour, the peak transmitter powe $r$ (measured rather poorly within the transmitter), and the limiting receiver sensitivities at each level.

\section{2 Methods of Analysis}

A typical period of recording consists of about 5 days in which meteor counts at the four levels have been continuously recorded for about 10 hours each day. This period of recording usually gives adequate coverage over the full 24 hours, albeit several days' data must be combined. An observed diurnal variation of rate representative of the week as a whole is thus obtained, and the sums of counts of each half hour over the total recording period of each day at each level of sensitivity are then normalized with respect to this observed diurnal rate curve. This allows for the fact that the se sums of counts are obtained over different and incomplete periods of the day, during which time the meteor detection rate varies quite markedly. These normalized sums of the half-hourly counts at each level for each day constitute the basic measures used to determine the absolute influx. For selected days of the year, Elford and Hawkins (1964) have related absolute influx to meteor counts, using an average radiant distribution derived from Havana meteors, and antenna patterns measured on model antennas. All we need to do is normalize our daily sums with respect to their data for the appropriate day 
of the year. Our sums, now fully normalized, represent values of $F$, the absolute mean influx averaged over the celestial sphere per unit solid angle at each level of sensitivity for each day of observation. The expression $\pi F(q)$ is the cumulative flux on the surface of the earth of meteors from the whole celestial sphere that produce trails with line densities greater than a given value $q$. Five days' observations thus give us about 20 values of $F$ as a function of sensitivity $S$, the latter being directly proportional to the minimum observable line density q.

\section{3 Discussion of Results}

A least-squares fit of $\log F$ against $\log S$ has been made for each week of observations, and the variation of the best value of $\log F$ at about the center of the dynamic range of the system is shown in Figure 1. Major showers have been excluded from the data. Verniani and Hawkins (1965) discussed a random sample of Havana meteors, in lieu of any better information we have related the limiting values of $q$ (in electrons per meter) to a limiting mass $m$ (in grams) by adopting the average ratio of $q$ to mass in their samples:

$\log \mathrm{m}_{\infty}=\log \mathrm{q}_{\max }-16.6$. The values of $\log F$ in Figure 1 , in fact, correspond to a calculated minimum meteor mass of $1 \times 10^{-5} \mathrm{gm}$. Considering our present poor knowledge of ionization probability, there is a large uncertainty in this value of limiting mass. It can be seen that there is slightly more than a factor of 2 variation in calculated influx during 1966, with the suggestion of a minimum in March 1967. The error bars represent statistical values of the $95 \%$ confidence limits, based only on the numerical data.

These figures should be treated very cautiously. Although we monitor the transmitter and receiver levels, other items of the equipment affect the counting rates. For example, the antennas and associated feeder lines were not monitored closely, and some deterioration was discovered in 1967 . Elford and Hawkins (1964) considered the motion of the ecliptic in the sky, but not a variation of meteor density along the earth's orbit. We have normalized our counts on the basis of their calculated rate variations throughout the year. These expected counts, for a constant value of influx $F$, are shown at the top of Figure 1 on a relative scale of the same amplitude as the 
computed values of $\log \mathrm{F}$ below. We see that a minimum in meteor rate is expected around March 21, which is when we have a suggestion of a minimum in the actual measures of the absolute influx F. This suggests that perhaps we have not allowed sufficiently for the annual variation; on the other hand, it may only be a coincidence. In any event, our data do not prove any variation in meteor influx from one year to another.

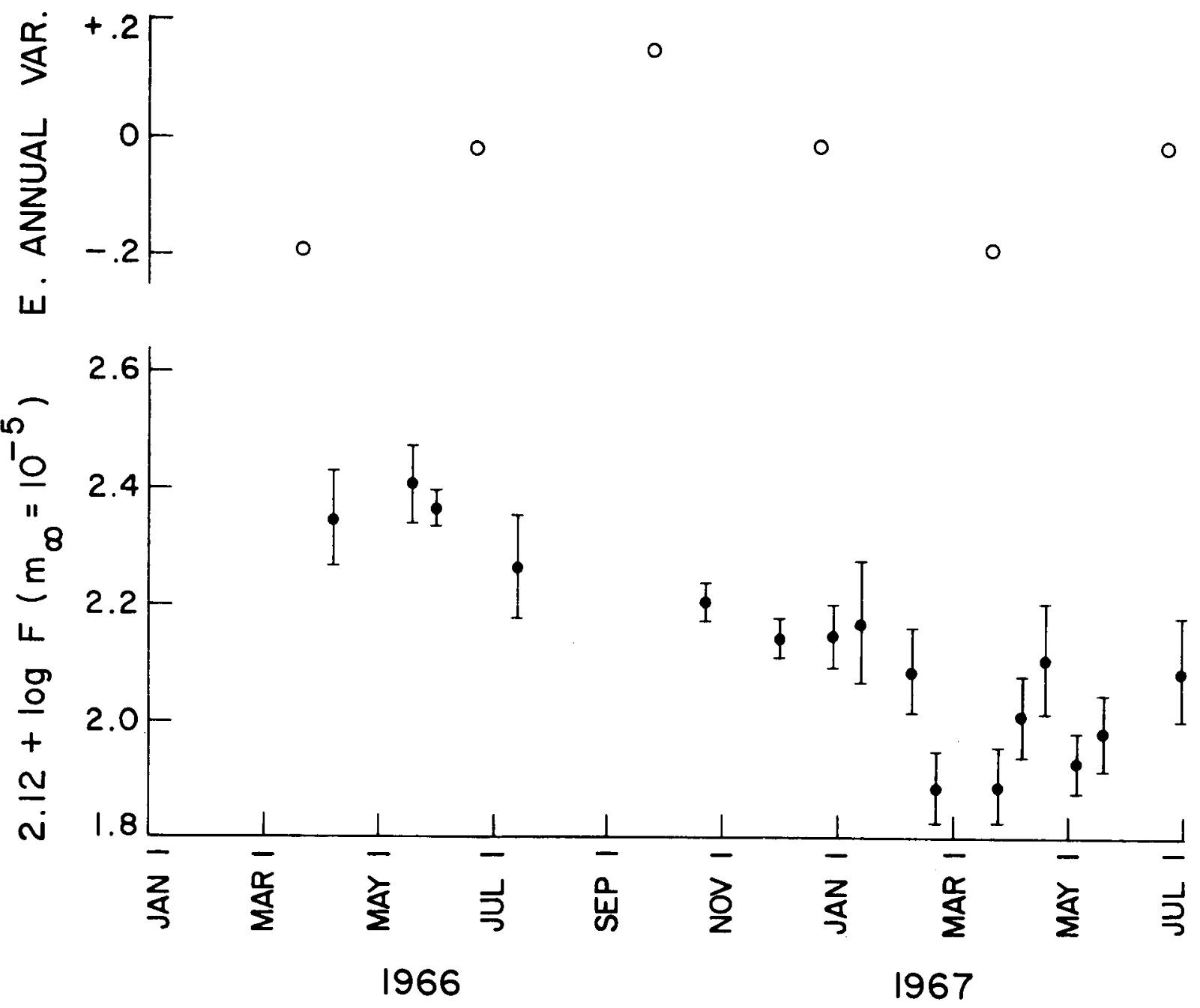

Figure 1. Top: The expected annual variation of meteor rate for constant $F$, plotted on the same scale as below. Bottom: Calculated values of $\mathrm{F}$ in meteors $\mathrm{km}^{-2} \mathrm{hr}^{-1}$, the flux per unit solid angle of the celestial sphere producing trails of maximum line densities $>3.9 \times 10^{1} 1$ electron $\mathrm{m}^{-1}$. 
The regression analyses of $\log F$ on $\log S$ give values of the slope of cumulative flux versus trail density for each weekly period of observation. These values generally fall between -1.0 and -1.1 , as can be seen from Figure 2. There does not appear to be any obvious regular variation over the year.

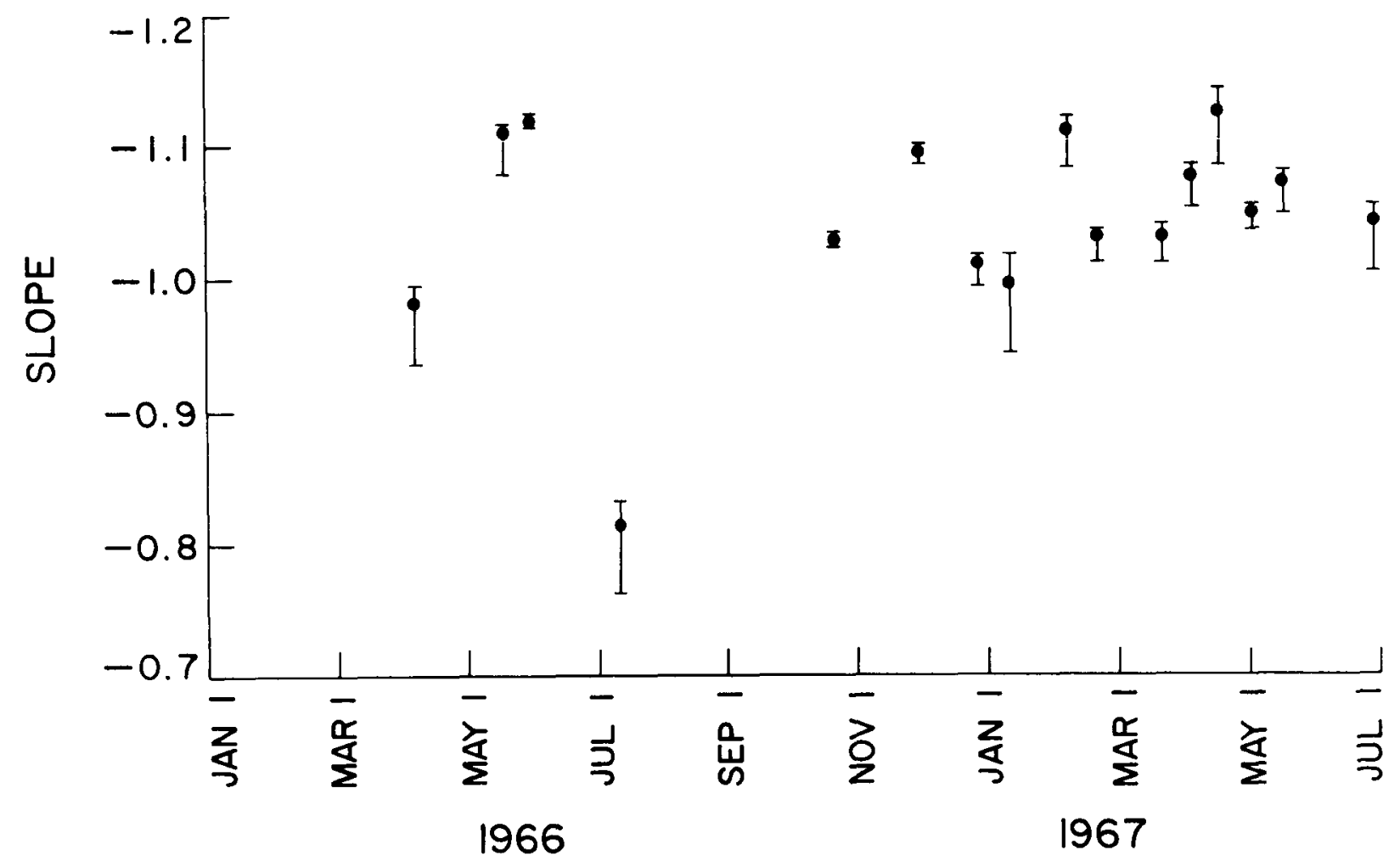

Figure 2. The calculated values of slopes of the cumulative flux versus sensitivity regression analyses.

If we pool all the data, we find that the cumulative influx I of meteors per square meter per second onto the surface of the earth is given by $\log I=-14.0-1.05 \log \mathrm{m}_{\infty}$. 


\section{MICROMETEOROID FLUX}

\subsection{Equipment}

The experiment flown on OGO-2 consists basically of four tubular detectors (see Figure 3). Each tube is about $10 \mathrm{~cm}$ long and $2.5 \mathrm{~cm}$ in diameter, forming a crude collimating system that restricts the angle of arrival of a particle detected on the rear sensors. Three of the four tubes point in mutually perpendicular directions. There are three sensors to each tube. A particle first passes through the two very thin films - each about $1500 \AA$ thick - at the front of each tube and gives rise to a small plasma pulse, which is used to start an oscillator to measure the time of flight down the tube. At the rear of the tube, the particle impacts destructively on a thin-film capacitor deposited on a glass disk. The pulse from this capacitor is used to stop the time-of-flight oscillator and to provide some measure of the energy of the particle. A microphone crystal is bonded to the rear of each glass disk to measure the momentum of the particle. The limiting sensitivity of the latter sensor is about $1 \times 10^{-4}$ dyne-sec; the capacitor sensor has been shown to respond to iron particles of $10^{-11} \mathrm{gm}$ impacting at speeds less than $3 \mathrm{~km}$ $\sec ^{-1}$. There are data to indicate it would respond to particles of mass less than $10^{-12} \mathrm{gm}$ at higher velocities, although the exact velocity dependence of this sensor has not been properly established. It is certainly the most sensitive sensor of the three in each tube.

A continuous in-flight calibration system monitored all these sensors and the associated electronics for the 1 year during which data were recorded. One rear capacitor sensor shorted out during this time, but this could not have been due to particle impact since the detector in question was the one used for noise control and was shielded from particle impact by a metal disk placed ahead of the front films. From these and other data we are reasonably sure the experiment has operated properly from launch in October 1965 at least through March 1966, the period for which data have been analyzed. 


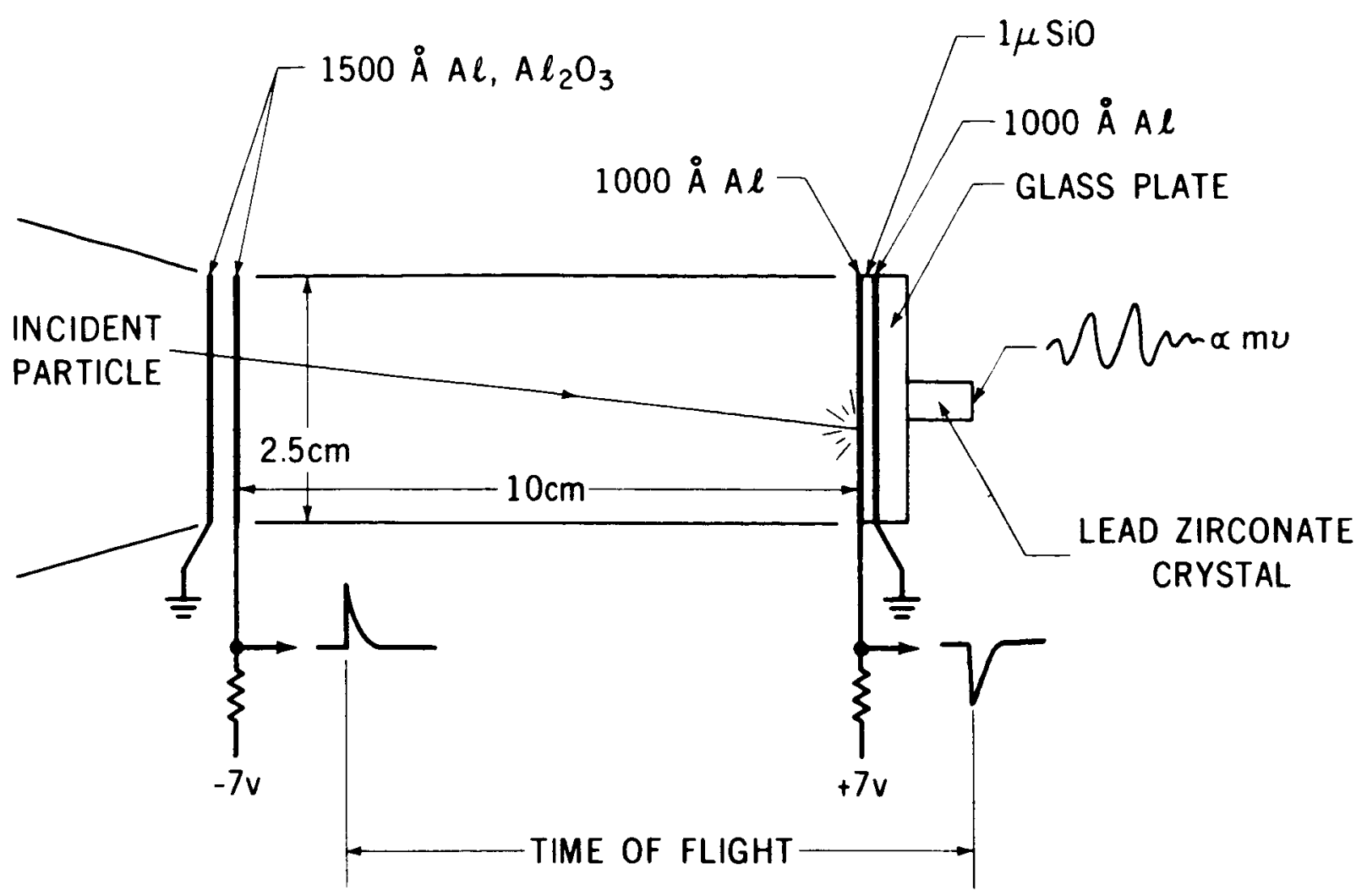

Figure 3. The basic OGO-2 micrometeoroid detector tube.

Sensor output data are recorded if either of the two rear sensors responds to an event. Noise or micrometeoroid events affecting only the front sensors would not appear in the OGO-2 data. Thus we have chosen as a criterion for the recognition of a micrometeoroid impact a response from at least the rear capacitor sensor. Furthermore, this event must not coincide with a command radioed to the spacecraft since some of these commands give rise to interference detected by the instrument.

\subsection{Results of Data}

More than a thousand events from the microphone sensors have been recorded. These events have not been associated with any genuine response from the other sensors and have been shown to be due to noise generated within the instrument itself under conditions of changing temperature 
(Nilsson, 1966). This conclusion, at least for this instrument, has been verified beyond any reasonable doubt by laboratory and in-flight tests.

Several hundred events, masquerading as micrometeoroid impacts, were recorded on the rear capacitor sensors in 1300 hours of data. In all but two cases, these events were traceable to electronic interference arising from commands sent to the spacecraft. We are thus left with two possible micrometeoroid impacts in 1240 hours of data. The probability of these two events being real must be considered low. The total effective area of all the rear sensors is $0.8 \mathrm{~cm}^{2}$ ster; hence, if we use these two possible events as an upper limit to the flux, we find that the average flux of particles of mass greater than $10^{-12}$ gm during the period October 1965 through March 1966 is less than $3 \times 10^{-2}$ particle $\mathrm{m}^{-2} \mathrm{sec}^{-1}(2 \pi \text { ster })^{-1}$.

More data remain to be analyzed; in addition, an improved instrument has recently been launched on the OGO-4 satellite. This latter experiment will record any events occurring on any of the sensors, alone or in conjunction with other sensor responses. Thus, particles impacting the front films but not reaching the rear sensors will be recognized and counted. The increased angle of acceptance will raise the effective area for flux measurement purposes to about $30 \mathrm{~cm}^{2}$ ster. This may eventually provide us with a reliable satellite measure of the flux of these small particles in the neighborhood of the earth

\section{3 Conclusion}

Figure 4 shows the radio meteor flux as a function of mass (designated on the figure as Radio Meteor Project 1967), together with the data point from OGO-2 (which is really only an upper limit). Some frequently published cumulative flux versus mass curves, as well as the satellite penetration data of Naumann (1966), have been added for comparison. From the three most recent results it appears that there is stili no radical departure from the 
constant mass per magnitude distribution of meteoric material in the neighborhood of the earth.

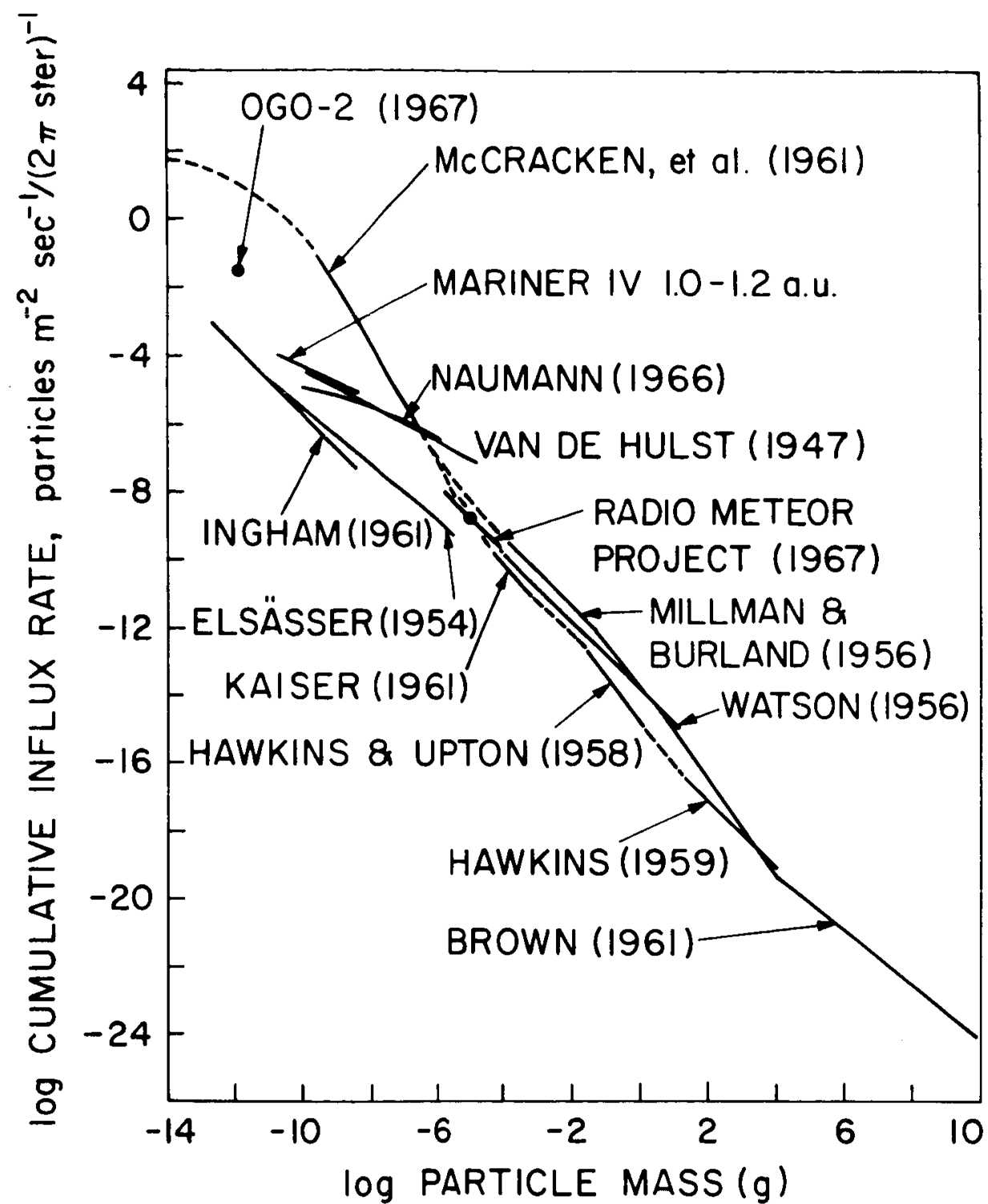

Figure 4. Cumulative flux versus mass curves based on data from various sources (originally drawn by C. W. McCracken and M. Dubin, NASA Tech. Note X-613-63-185, 1963). (References may be found in original text.) 


\section{ACKNOWLEDGMENTS}

The authors wish to acknowledge the work of W. M. Alexander, now at Temple University, Philadelphia, Pennsylvania, and others in the design and construction of the OGO-2 micrometeoroid experiment at Goddard Space Flight Center, Greenbelt, Maryland. 


\section{REFERENCES}

ELFORD, W. G. AND HAWKINS, G. S.

1964. Meteor echo rates and the flux of sporadic meteors. Harvard Radio Meteor Project Report No. 9, 24 pp.

NILSSON, C. S.

1966. Some doubts about the earth's dust cloud. Science, vol. 153, pp. $1242-1246$.

NAUMANN, R. J.

1966. The near-earth meteoroid environment. NASA Tech. Note D-3717, pp. $1-38$.

VERNIANI, F. AND HAWKINS, G. S.

1965. Masses, magnitudes, and densities of 320 radio meteors. Harvard Radio Meteor Project Report No. 12, 35 pp. 


\section{BIOGRAPHICAL NOTES}

CARL S. NILSSON received the B.Sc. and Ph. D. degrees from the University of Adelaide, Australia, in 1955 and 1963, respectively.

Before joining the staff at SAO, Dr. Nilsson was a research associate at the Goddard Space Flight Center, Maryland.

Since he came to SAO in 1966, his work has been directed toward problems in total flux of extraterrestrial material into the earth's atmosphere and the orbital distribution of the meteors in the solar system. He is the principal investigator for micrometeoroid experiments on the OGO-2 and OGO-D satellites.

RICHARD B. SOUTHWORTH received the B.A. degree from Swarthmore College in 1950, and the M.A. and Ph. D. degrees from Harvard University in 1960 and 1961, respectively.

Prior to his association with SAO, Dr. Southworth held research assistantships at Massachusetts Institute of Technology and Harvard College Observatory.

His investigations at SAO since his appointment as staff physicist in 1961 cover meteors, comets, and the zodiacal cloud. 


\section{NO TICE}

This series of Special Reports was instituted under the supervision of Dr. F. L. Whipple, Director of the Astrophysical Observatory of the Smithsonian Institution, shortly after the launching of the first artificial earth satellite on October 4, 1957. Contributions come from the Staff of the Observatory.

First is sued to ensure the immediate diss emination of data for satellite tracking, the reports have continued to provide a rapid distribution of catalogs of satellite observations, orbital information, and preliminary results of data analyses prior to formal publication in the appropriate journals. The Reports are also used extensively for the rapid publication of preliminary or special results in other fields of astrophysics.

The Reports are regularly distributed to all institutions participating in the U.S. space research program and to individual scientists who request them from the Publications Division, Distribution Section, Smithsonian Astrophysical Observatory, Cambridge, Massachusetts 02138 . 